\title{
10-12 Yaş Grubu Yüzücülerde Uygulanan 8 Hafta Reaksiyon Antrenmanlarının Etkilerinin İncelenmesi
}

\author{
Sezen POLAT ${ }^{1}$ \\ Eralp ERBAŞ ${ }^{1}$ \\ Özlem ORHAN ${ }^{1}$
}

${ }^{1}$ Gazi Üniversitesi, Spor Bilimleri Fakültesi, Antrenörlük Ĕgitimi, ANKARA

Künye: Polat, S., Eralp, E. ve Orhan, Ö. (2018). 10-12 Yaş Grubu Yüzücülerde Uygulanan 8 Hafta Reaksiyon Antrenmanlarının Etkilerinin İncelenmesi. Gaziantep Üniversitesi Spor Bilimleri Dergisi, 3(3): 59-66.

\section{Öz}

Bu araştırmada 10-12 yaş grubu yüzücülerde uygulanan 8 haftalık reaksiyon antrenmanlarının etkilerinin incelenmesi amacıyla yapılmıştır. Araştırmaya yarışmacı

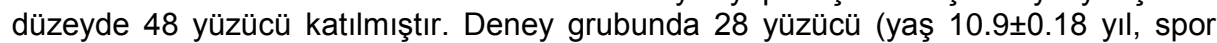
yaşı $5.43 \pm 0.28 \mathrm{yıl}$, boy uzunluğu $151.1 \pm 2.24 \mathrm{~cm}$, vücut ağırlığı $41.2 \pm 2.12 \mathrm{~kg}$, BKI17.9 $\pm 0.4 \mathrm{~kg}$ ) kontrol grubu ise 20 yüzücüden oluşmuştur (yaş $11.1 \pm 0.17 \mathrm{yıl}$, spor yaşı $3.55 \pm 0.22$, boy uzunluğu $144.7 \pm 1.39 \mathrm{~cm}$, vücut ağırlığı $37.4 \pm 1.86 \mathrm{~kg}$, BKI $18.1 \pm 0.73 \mathrm{~kg}$ ). Deneklere işitsel sağ ve sol el reaksiyon testi uygulamış ve testlerin her biri üçer kez uygulanarak en iyi süre kaydedilmiştir. Verilerin analizi SPSS 23.0 paket programında yapılmıştır. Grup içi ön test ve son testler arasında farklılık olup olmadığını tespit etmek için Willcoxon T testi, iki grup arasında fark olup olmadığını belirlemek için Mann Whitney $U$ testi uygulanmıştır. İstatiksel olarak anlamlılık düzeyi p $<0.05$ olarak kabul edilmiştir. Çalışma sonucunda deney grubunun sağ ve sol el reaksiyon değerleri kontrol grubu ile karşılaştırıldığında \%95 güven aralığında grup içi ve gruplar arasında sağ ve sol el parametrelerinde istatistiksel açıdan anlamlı bir farklılık tespit edilmiştir $(p<0.05)$. Sonuç olarak yüzme antrenmanları ile birlikte yapılan reaksiyon antrenmanlarının yüzücülerin reaksiyon zamanlarını geliştirdiği söylenebilir.

\section{Orijinal Makale}

Yayın Bilgileri

Gönderi Tarihi: 11.07.2018

Kabul Tarihi: 11.09 .2018

Yayın Tarihi: 24.09.2018

Sorumlu Yazar

e-mail: sezencimen@gazi.edu.tr

DOI: $10.31680 / g a u n j s s .442373$

Anahtar Kelimeler: Yüzme, Reaksiyon zamanı

\section{The Effect of 8 Week Reaction Trainings on Reaction Times 10-12 Ages Swimmers}

\begin{abstract}
This study was conducted to examine the effects of 8-week reaction training on reaction times of 10-12-year-old swimmers. 28 swimmer test groups (age: $10.9 \pm 0.18$ years, gender of $5.43 \pm 0.28$ years, height of $151.1 \pm 2.24 \mathrm{~cm}$, body weight of $41.2 \pm$ $2.12 \mathrm{~kg}$, BMl of $17.9 \pm 0.4 \mathrm{~kg}$ ) and 20 swimmer control groups year, sport age: $3.55 \pm$ 0.22 , height: $144.7 \pm 1.39 \mathrm{~cm}$, body weight: $37.4 \pm 1.86 \mathrm{~kg}$, BMl: $18.1 \pm 0.73 \mathrm{~kg}$ ). Audiological left and right hand reaction tests were applied to the subjects and the best time was recorded by applying each test three times. Analysis of the data was done in SPSS 23.0 package program. The Willcoxon $T$ test was used to determine whether there was a difference between the pre-test and post-test in the group, and the Mann-Whitney $U$ test was used to determine the difference between the two groups. Statistically significant level of $p<0.05$ was accepted. When the right and left hand reaction values of the experimental and control groups were compared, there was a statistically significant difference between right and left hand parameters in the $95 \%$ confidence interval $(p<0.05)$. As a result, it can be said that the reaction training with swimming training improves the reaction times of swimming.
\end{abstract}

\section{Original Article}

\section{Article Info}

Received: 11.07 .2018

Accepted: 11.09 .2018

Published: 24.09.2018

Corresponding Author

e-mail: sezencimen@gazi.edu.tr

Key Words: Swimming, Reaction time 


\section{Giriş}

Yüzme kas gücü, dayanıklılık, sürat, koordinasyon, beceri ve reaksiyon gerektiren bir spor dalıdır (Sokolovas, 2006). Yüzmede amaç, iyi bir çıkış yaparak belli mesafeyi belirlenmiş kurallara uygun olarak en kısa sürede tamamlamaktır. Bu sebeple yüzme, sürat ve reaksiyonun yanı sıra hareket ve ritim algısını da içeren karmaşık becerilerden meydana gelmektedir (Hanula,2001). Sporcunun yarışma başlangıcındaki reaksiyon zamanı, vücudun yer değiştirme sürati ve kulaç sıklığı yüzme performansını etkileyen faktörler arasındadır.

Kişiye bir uyaranın verilmesi ile kişinin bu uyarana istemli olarak verdiği cevabın başlangıcı arasındaki geçen zaman birimi reaksiyon zamanı olarak tanımlanmıştır (Akgün,1986). Reaksiyon zamanı, uyaranın verilmesi ile başlar ve hareket tepkisinin gösterilmesi ile sonlanır. Reaksiyon süresi yaş, antrenman durumu, merkezi ve periferik yorgunluk düzeyine bağlı olarak değişmektedir (Cojocariu,2011).

Performans ve zaman faktörü, sporcu ve antrenörlerin her zaman ilgi alanı olmuş ve değişik nedenlerden dolayı bunlar arasındaki ilişki araştırma konusu olmuştur. Yapılan çalışmalarda fiziksel antrenman ile reaksiyon zamanının kısaltılabileceği ortaya konmuştur (Çolakoğlu ve ark., 1993; Genevois ve ark., 2013; Salonikidis ve Zafeiridis, 2008; Panton ve ark.,1990). Hollman basit reaksiyon zamanının antrenmanla \%10-15, karmaşık reaksiyon zamanının ise \%30-40 oranında kısaltılabileceğini belirtmiştir (Hollman,1990). Reaksiyon zamanı her ne kadar doğuştan gelen bir yetenek olsa da çalışmalarla geliştirilebilen motorik bir özellik olarak kabul edilmektedir. Reaksiyon zamanı çoğu sporda belirleyici bir etmendir ve düzenli antrenmanlar aracılığı ile geliştirilebilir.

Yüzme antrenmanları ile beraber uygulanan reaksiyon antrenmanlarının yarışma performansı üzerinde etkili olabileceği düşünülerek yola çıkılan bu çalışmanın amacı 8 haftalık reaksiyon antrenmanlarının 10-12 yaş grubu yüzücülerin reaksiyon zamanlarına etkilerini incelemektir.

\section{Yöntem}

Bu çalışma Ankara'da bulunan Aykon ve Ankara İhtisas Spor Kulüplerinde aktif olarak yüzme antrenmanlarına katılan toplam 48 kız (26) ve erkek (22) yüzücü

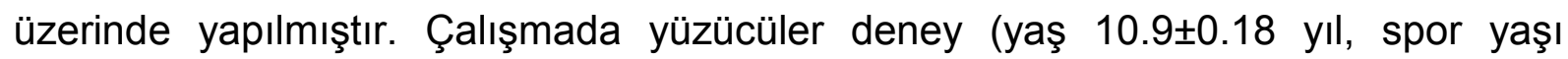
$5.43 \pm 0.28$ yıl, boy uzunluğu $151.1 \pm 2.24 \mathrm{~cm}$, vücut ağırlığı $41.2 \pm 2.12 \mathrm{~kg}, \mathrm{BKI} 17.9 \pm 0.4$ $\mathrm{kg}$ ) ve kontrol (yaş 11.1 $\pm 0.17 \mathrm{yll}$, spor yaşı $3.55 \pm 0.22$, boy uzunluğu $144.7 \pm 1.39 \mathrm{~cm}$, 
vücut ağırlığı $37.4 \pm 1.86 \mathrm{~kg}$, BKI $18.1 \pm 0.73 \mathrm{~kg}$ ) grubu olarak ikiye bölünmüştür. Deney ve kontrol grupları oluşturulurken öncelikle sporcular yaşlarına göre sınıflandırılmışlardır. Daha sonra aynı yaş grubundan rastlantısal yöntem ile deney grubuna $(n=28)$ bir sporcu kontrol grubuna $(n=20)$ tüm sporcular dağıtılmıştır. Araştırmada ön test-son test olmak üzere, kontrol ve deney grubuna iki ölçüm yapılmıştır. Denekler ölçümler ile ilgili olarak bilgilendirilmiştir. Katılacak deneklerin aileleri gönüllü onam formu imzalayarak çalışmaya onay vermişlerdir.

\section{Reaksiyon Antrenmanı İçeriği}

Deney grubuna 8 hafta süresince haftada 5 gün yüzme antrenmanları ile birlikte ek olarak haftada üç gün reaksiyon antrenmanları yaptırılmıştır. Kontrol grubuna ise sadece haftada 5 gün yüzme antrenmanları uygulanmışır. Reaksiyon antrenmanı deney grubuna haftada üç gün hem karada hem suda uygulanmıştır.

Reaksiyon antrenmanı; kara antrenmanları esnasında ve su antrenmanları öncesinde her antrenman yaklaşık $30 \mathrm{dk}$ sürecek biçimde uygulanmıştır. Reaksiyon antrenmanı öncesinde yüzücüler branşlarına özgü kendi ısınmalarını uygulamışlardır. Reaksiyon çalışmalarında sesli uyaran olarak düdük, sesli komutlar kullanılmıştır. Dışarıdan sesli uyaran ile vücudun bölümleri söylenerek (baş, omuz, diz) en çabuk şekilde dokunmaları istenmiştir. Deneklerden arkaları dönük şekilde durmaları istenmiş ve komutla 180 derece dönüp atılan tenis topunu yakalamaları istenmiştir. Depar taşında hazır komutuyla bekleyip farklı seslerle çıkış yapmaları istenmiştir. Yine depar taşında bekleyip önceden belirtilen sesli komutla çıkmaları söylenerek yanıltıcı uyaranlarda verilerek çıkış yapmaları sağlanmışıı Yerde streamline pozisyonunda yüzüstü beklerken komutla hızlı bir şekilde kalkıp 10m sürat koşusu yapmaları istenmiştir. Başka bir çalışma olarak streamline pozisyonunda beklerken komutla yukarıya sıçramaları istenmiştir. Tenis topu ve sesli uyaranlar kullanılarak farklı mesafelerde, farklı pozisyonlarda eşli ve eşsiz olarak çalışmalar uygulanmıştır. (Antrenör ve sporcu yüz yüze bakarken antrenörün elindeki tenis topunu sporcu elleri arkada bekler ve sesli komutla bırakılan topları yakalamaya çalışır. Denek duvara karşı durur. Topu sağ eli ile duvara atar ve sol eliyle karşılar. İkinci çalışmada ise gelen sesli uyarana göre elini uzatır ve tutmaya çalışır). 


\section{Boy Uzunluğu}

Boy ölçümü için Seca marka taşınabilir boy ölçüm cihazı kullanılmıştır. Deneklerin boy uzunlukları; anatomik duruşta, çıplak ayak, ayak topukları birleşik, baş frontal düzlemde, baş üstü tablası verteks noktasına değecek şekilde pozisyon alındıktan sonra, ölçüm cm olarak kaydedilmiştir.

\section{Vücut Ağırlığı}

Vücut ağırığı ölçümleri dijital ölçüm cihazıyla (Seca) yapılmıştır. Deneklerin vücut ağırlıkları; uygun spor kıyafet, çıplak ayak ve anatomik duruş pozisyonunda iken kg olarak ölçülmüştür.

\section{Beden Kitle İndeksi}

Vücut kompozisyonu ölçümü TANITA BC-420SMA Body Composition Analyzer ile alınmıştır. Biyoelektrik impedans analizi, katıımcılara uygun spor kıyafeti ile ve üzerlerinde herhangi bir metal aksam, takı vb. olmadan çıplak ayak ile cihazın üzerine çıkmaları sağlanarak uygulanmıştır.

\section{Reaksiyon Zamanı Ölçümü}

Deneklerin işitsel reaksiyon zamanı (sağ-sol el) New Test 2000 reaksiyon ölçüm cihazı ile yapılmıştır. Testlerin her biri üçer kez yapılmış ve en iyi süre kaydedilmiştir.

\section{Verilerin Analizi}

Verilerin analizi SPSS 23.0 paket programında yapılmıştır. Grup içi ön test ve son testler arasında farklılık olup olmadığını tespit etmek için Willcoxon $\mathrm{T}$ testi uygulanmış ve iki grup arasında fark olup olmadığını belirlemek için, Mann Whitney U testi kullanılmıştır. İstatiksel olarak anlamlılık düzeyi $p<0.05$ olarak kabul edilmiştir. 


\section{Bulgular}

Tablo 1. Boy Uzunluğu, Vücut Ağırlığı, Beden Kitle İndeks, Vücut Yağ Yüzdesi Değerlerinin Karşılaştırması

\begin{tabular}{|c|c|c|c|}
\hline Parametreler & Grup & 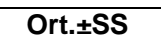 & $p$ \\
\hline \multirow{2}{*}{ Yaş } & Deney (28) & $10.9 \pm 0.18$ & \multirow{2}{*}{0.44} \\
\hline & Kontrol (20) & $11.1 \pm 0.17$ & \\
\hline \multirow{2}{*}{ Spor Yaşı } & Deney (28) & $5.43 \pm 0.28$ & \multirow{2}{*}{$0.00^{*}$} \\
\hline & Kontrol (20) & $3.55 \pm 0.22$ & \\
\hline \multirow{2}{*}{ Boy Uzunluğu (cm) } & Deney (28) & $151.1 \pm 2.24$ & \multirow{2}{*}{0.11} \\
\hline & Kontrol (20) & $144.7 \pm 1.39$ & \\
\hline \multirow{2}{*}{ Vücut Ağırlığı (kg) } & Deney (28) & $41.2 \pm 2.12$ & \multirow{2}{*}{0.29} \\
\hline & Kontrol (20) & $37.4 \pm 1.86$ & \\
\hline \multirow{2}{*}{$\mathrm{BKI}(\mathrm{kg})$} & Deney (28) & $17.9 \pm 0.4$ & \multirow{2}{*}{0.5} \\
\hline & Kontrol (20) & $18.1 \pm 0.73$ & \\
\hline
\end{tabular}

Tablo 1 incelendiğinde, deneklerin yaş (yıl), boy uzunluğu $(\mathrm{cm})$, vücut ağırlığı $(\mathrm{kg})$ ve BKI (kg) değerlerinde \%95 güven aralığında istatistiksel olarak bir fark tespit edilmezken, spor yaşlarında (yı) istatistiksel açıdan anlamlı bir farklılık tespit edilmiştir $(p<0.05)$.

Tablo 2. Sağ ve Sol El İşitsel Reaksiyon Değerlerinin Karşılaştırılması

\begin{tabular}{|c|c|c|c|c|c|}
\hline \multirow{2}{*}{ Parametreler } & \multirow{2}{*}{ Grup } & Ön-Test & Son-Test & Grup İçi & $\begin{array}{c}\text { Gruplaı } \\
\text { Arası }\end{array}$ \\
\hline & & Ort. $\pm S S$ & Ort. $\pm S S$ & $p$ & $p$ \\
\hline \multirow{2}{*}{$\begin{array}{c}\text { Sağ El İşitsel } \\
\text { Reaksiyon (msn) }\end{array}$} & Deney (28) & $232.5 \pm 8.03$ & $205.9 \pm 6.39$ & $0.00 *$ & \multirow{2}{*}{$0.00^{*}$} \\
\hline & Kontrol (20) & $259.4 \pm 14.5$ & $257.4 \pm 13.1$ & 0.4 & \\
\hline \multirow{2}{*}{$\begin{array}{c}\text { Sol El İşitsel } \\
\text { Reaksiyon (msn) }\end{array}$} & Deney (28) & $249.1 \pm 8.73$ & $220.9 \pm 8.59$ & $0.00^{*}$ & \multirow{2}{*}{$0.00^{*}$} \\
\hline & Kontrol (20) & $268.1 \pm 15.4$ & $268 \pm 15.1$ & 0.87 & \\
\hline
\end{tabular}
$p<0.05$

Tablo 2 incelendiğinde, deney ve kontrol grubunun reaksiyon değerleri \%95 güven aralığında grup içi ve gruplar arası işitsel reaksiyon sağ ve sol el parametrelerinde istatistiksel açıdan anlamlı bir farklılık tespit edilmiştir $(p<0.05)$.

\section{Tartışma ve Sonuç}

Yapılan çalışmada 8 haftalık reaksiyon antrenmanlarının yüzücülerin reaksiyon zamanları üzerine etkisi araştırılmıştır. Araştırma sonucunda deneklerin yaş (yıl), boy uzunluğu $(\mathrm{cm})$, vücut ağırlığı $(\mathrm{kg})$ ve BKI $(\mathrm{kg})$ değerlerinde istatistiksel 
olarak bir fark tespit edilmezken, spor yaşlarında (yıl) istatistiksel açıdan anlamlı bir farklılık tespit edilmiştir $(p<0.05)$. Deney ve kontrol grubunun grup içi ve gruplar arası işitsel reaksiyon sağ ve sol el parametrelerinde istatistiksel açıdan anlamlı bir farklıık tespit edilmiştir $(p<0.05)$.

Yüzme sporunda, sporcunun su içinde belirlenmiş mesafeleri, belirlenmiş tekniklerle en kısa zamanda kat edebilmesi için pek çok farklı yeteneğinin iyi geliştirilmiş ve antrene edilmiş olması oldukça büyük önem taşımaktadır. Bu özelliklerin belli ölçümlerle belirlenmesi ve uygun antrenmanlarla geliştirilmesi yüzücünün performansı için etkili olacaktır (Siders, ve ark., 1993). Reaksiyon, tepki ve cevap süresi premotor ve motor elemanlar olarak ikiye ayrılır. Motor kontrol, merkezi sinir sistemi tarafından proprioseptörler aracılığı ile kontrol edilir. Reaksiyon zamanının öğrenme ve deneyim ile ilişkili bir beceri olduğu söylenebilir. Reaksiyon zamanının ölçümü özellikle kısa mesafe koşularında ya da bir yüzücünün startında çok önemlidir. Reaksiyon zamanı diğer aktivitelerin de bir parçası olarak düşünülmelidir. Birçok hızlı hareketin başarısı, sporcunun göstermiş olduğu reaksiyona bağlıdır. Çünkü reaksiyon zamanı birçok becerinin temel komponenti (elemanı) olarak görülmektedir (Rudisill,1992).

Literatürde bu güne kadar sporcuların yüzme performansını etkilediği düşünülen pek çok parametre araştırımıştır. Boy uzunluğu ve vücut ağırığı, yağ yüzdesi, farklı ısınma protokolleri ve beden kitle indeksi ilişkileri bu parametrelere örnek olarak verilebilir (Balilionis ve ar., 2012; Cassell ve ark., 1996). Ancak yüzme ve reaksiyon ilişkisinin incelendiği herhangi bir çalışmaya rastlanılmamıştır. Reaksiyon zamanı ile yapılan çalışmalar incelendiğinde, Salonikidis ve Zafeiridis'in (2008) tenisçiler üzerinde yapmış oldukları çalışmada; tenis antrenmanları dışında uygulanan reaksiyon antrenman programının reaksiyon zamanını düşürerek olumlu etkilediği ve bu değişimin hem sadece tenis drillerinin kullanıldığı hem de kombine olarak uygulanan antrenman modelinde görüldüğünü belirtmişlerdir. Moka ve arkadaşları kadın hokey oyuncuları üzerinde yaptıkları çalışmada reaksiyon antrenmanlarının hokeycilerin reaksiyon zamanlarını olumlu yönde etkilediğini bulmuşlardır (Moka ve ark., 1992). Çankaya ve arkadaşları 11 yaş erkek öğrenciler üzerinde uyguladıkları denge antrenmanlarının reaksiyon zamanlarında iyileşme sağladığını belirtmişlerdir (Çankaya ve ark., 2014). İmamoğlu ve Kılcıgil (2007), yaptıkları çalışmalarında Türkiye'deki minik futbolcuların eğitiminde teknik ve taktik becerilerin yanı sıra reaksiyon antrenmanlarının da yaptırılması gerekliliğini yaptıkları 
çalışmada önemle vurgulamışlardır. Kısa mesafe koşucuları üzerinde yapılan bir başka çalışmada ise antrenman programları ile birlikte yapılan reaksiyon çalışmalarının reaksiyon zamanını olumlu etkilediği ve bunun da motor kontrolü arttırabileceği belirtilmiştir (Collect, 1999).

Reaksiyon zamanının sprint ve çıkış gerektiren spor dallarında rol oynayan önemli bir özellik olduğu belirtilmektedir. Sporcular için gerekli motorsal bir özellik olan reaksiyon zamanı çoğu sporlarda belirleyici bir faktördür ve düzenli antrenmanlarla geliştirilebilir (Salonikidis ve Zafeiridis,2008). Reaksiyon zamanının önemli olduğu spor branşlarında uyarıya verilen cevabın şiddetine bakarak sporcunun başarılı ya da başarısız olarak tanımlanabileceği belirtilmektedir.

Yapılan çalışma da sonuç olarak, 10-12 yaş grubu yüzücülerde uygulanan reaksiyon antrenmanlarının reaksiyon zamanının iyileştirmesine olumlu katkıda bulunduğu tespit edilmiştir. Bu bakımdan 10-12 yaş grubu çocukların genel antrenmanlarına ek olarak uygulanan reaksiyon antrenmanlarının yüzücülerin performanslarına katkı sağlayabileceği ve su içinde farklı mesafelerdeki derecelerinin iyileştirebileceği söylenebilir.

\section{Kaynaklar}

Akgün N. (1986). Egzersiz Fizyolojisi. İzmir: Ege Üniversitesi Basımevi.

Balilıonis G, Nepocatych S, Ellis C M, Richardson M T, Neggers $Y$ H,Bishop P A. (2012). Effects Of Different Types Of Warm-Up On Swimming Performance, Reaction Time, And Dive Distance. Journal of Strength and Conditioning Research. 26(12): 3297-3303.

Cassell C, Benedict M, Spoecker B. (1996). Bone Mineral Density In Elite 7 to 9 Years Old Female Gymnasts and Swimmers. Medicine and Science in Sports and Exercices. 28(10): 1243-1246.

Cojocariu A.(2011). Measurement Of Reaction Time In Qwan Ki Do. Biology of Sport. 28(2): 139-143.

Collet C. (1999). Strategic Aspects Of Reaction Time In World-Class Sprinters. Perceptual and Motor Skills. 88(1): 65-75.

Çankaya S, Gökmen, B., Çon M. Taşmektepligil M Y. (2014). Denge Geliştirici Özel Antrenman Uygulamalarının 11 Yaş Genç Erkeklerin Reaksiyon Zamanları Ve Vücut Kitle İndeksi Üzerine Etkisi. Spor ve Performans Araştırmaları Dergisi. 5(2): 59-67. 
Çolakoğlu,M.,Tiryaki, Ş, Moralı,S. (1993). Konsantrasyon Çalışmalarının Reaksiyon Zamanı Üzerine Etkisi. Hacettepe Üniversitesi Spor Bilimleri Dergisi. 4(4): 3247.

Genevois C, Frican B, Creveaux T, Hautier C, Rogowski I. (2013). Effects Of Two Training Protocols On The Forehand Drive Performance In Tennis. The Journal of Strength \& Conditioning Research. 27(3): 677-82.

Hanula D. (2001). The Swim Coaching Bible. USA: Human Kinetics.

Hollman W. (1990). Training-Grundlagen Und Adaptation Aus PhysiologisschMedizinischer Sicht Studienbrief 9, Trainerakademie-Köln, 216-217.

İmamoğlu O, Kılcıgil E. (2007). Türkiye'deki Minik Futbolcularda Reaksiyon Zamanı,

Vital Kapasite Değerleri Ve Laterizasyon Dağılılımında Solaklık Sorunu. Spormetre Beden Eğitimi ve Spor Bilimleri Dergisi. 5(3): 95-100.

Moka R, Kaur G, Sidhu L. (1992). Effect Of Training On The Reaction Time of Indian Female Hockey Players. The Journal of Sports Medicine and Physical Fitness. 32(4): 428-431.

Panton LB, Graves, JE, Pollock, ML, Hagberg, JM, and Chen, W.(1990). Effect Of Aerobic And Resistance Training On Fractionated Reaction Time And Speed Of Movement. Journal of Gerontology. 45(1): 26-31.

Rudisill M. (1992). The Effect Of Physical Activity Programme On Reaction Time On Time For Older Adult. Journal of Human Movement Studies. 22: 205-212

Salonikidis K, Zafeiridis A. (2008).The Effects Of Plyometric, Tennis-Drills, And Combined Training On Reaction, Lateral And Linear Speed, Power, And Strength in Novice Tennis Players. The Journal of Strength and Conditioning Research. 22(1): 182-91.

Siders, W A., Lukaski, H C., Bolonchuk, W W. (1993). Relationships Among Swimming Performance, Body Composition And Somatotype In Competitive Collegiate Swimmers. Journal Of Sports Medicine And Physical Fitness. 33(2): 166-171.

Sokolovas, G. (2006). Analysis of USA swimming's all-time top 100 times. In J. P. Vilas-Boas, F. Alves, \& A. Marques (Eds.), Proceedings of the Xth International Symposium on Biomechanics and Medicine in Swimming, 315-317. Porto: University of Porto. 